\title{
Effects of subacute ruminal acidosis challenges on fermentation and endotoxins in the rumen and hindgut of dairy cows
}

\author{
S. Li, E. Khafipour, D. O. Krause, A. Kroeker, J. C. Rodriguez-Lecompte, G. N. Gozho, and J. C. Plaizier ${ }^{1}$ \\ Department of Animal Science, University of Manitoba, Winnipeg, MB, Canada R3T 2N2
}

\begin{abstract}
The effects of a grain-based subacute ruminal acidosis (SARA) challenge (GBSC) and an alfalfa-pellet SARA challenge (APSC) on fermentation and endotoxins in the rumen and in the cecum, as well as on endotoxins in peripheral blood, were determined. Six nonlactating Holstein cows with cannulas in the rumen and cecum were used in the study. A $3 \times 3$ Latin square arrangement of treatments with 4-wk experimental periods was adopted. During the first $3 \mathrm{wk}$ of each experimental period, all cows received a diet containing $70 \%$ forages [dry matter (DM) basis]. In wk 4 of each period, cows received 1 of the following 3 diets: the $70 \%$ forage diet fed during wk 1 to 3 (control), a diet in which $34 \%$ of the dietary DM was replaced with grain pellets made of $50 \%$ ground wheat and $50 \%$ ground barely (GBSC), or a diet in which $37 \%$ of dietary DM was replaced with pellets of ground alfalfa (APSC). Rumen $\mathrm{pH}$ was monitored continuously using indwelling $\mathrm{pH}$ probes, and rumen fluid, blood, cecal digesta, and fecal grab samples were collected immediately before feed delivery at $0900 \mathrm{~h}$ and at $6 \mathrm{~h}$ after feed delivery on $\mathrm{d} 3$ and 5 of wk 4 . The time for which rumen $\mathrm{pH}$ was below 5.6 was $56.4,225.2$, and $298.8 \mathrm{~min} / \mathrm{d}$ for the control, APSC, and GBSC treatments, respectively. Compared with the control, SARA challenges resulted in similar reductions in cecal digesta $\mathrm{pH}$, which were $7.07,6.86$, and 6.79 for the control, APSC, and GBSC treatments, respectively. Compared with the control, only GBSC increased starch content in cecal digesta, which averaged 2.8, 2.6, and $7.4 \%$ of DM for the control, APSC, and GBSC, respectively. Free lipopolysaccharide endotoxin (LPS) concentration in rumen fluid increased from 10,405 endotoxin units $(\mathrm{EU}) / \mathrm{mL}$ in the control treatment to 30,715 and $168,391 \mathrm{EU} / \mathrm{mL}$ in APSC and GBSC, respectively. Additionally, GBSC increased the LPS concentration from 16,508 to $118,522 \mathrm{EU} / \mathrm{g}$ in wet cecal digesta, and from 12,832 to $93,154 \mathrm{EU} / \mathrm{g}$ in wet feces. The APSC treatment did not affect LPS
\end{abstract}

Received April 13, 2011.

Accepted September 14, 2011.

${ }^{1}$ Corresponding author: plaizier@ms.umanitoba.ca concentrations in cecal digesta and feces. All concentrations of LPS in blood plasma were below the detection limit of $>0.05 \mathrm{EU} / \mathrm{mL}$ of the technique used. Despite the absence of LPS in blood, only GBSC increased the concentration of LPS-binding protein in blood plasma, which averaged, 8.9, 9.5, and $12.1 \mathrm{mg} / \mathrm{L}$ for the control, APSC, and GBSC treatments, respectively. This suggests that GBSC caused translocation of LPS from the digestive tract but that LPS was detoxified before entering the peripheral blood circulation. The higher LPS concentration in cecal digesta in the GBSC compared with the APSC suggests a higher risk of LPS translocation in the large intestine in GBSC than in APSC.

Key words: subacute ruminal acidosis, endotoxin, cecum, fermentation

\section{INTRODUCTION}

Feeding high-grain diets to induce subacute ruminal acidosis (SARA) in dairy cows has consistently been associated with increases in the concentrations of LPS endotoxin originating from gram-negative bacteria in rumen fluid (Andersen et al., 1994; Khafipour et al., 2009a; Zebeli and Ametaj, 2009), and of acute phase proteins, including LPS-binding protein (LBP), in peripheral blood (Andersen et al., 1994; Khafipour et al., 2009a; Zebeli and Ametaj, 2009). Changes in the levels of acute phase proteins are indicative of a systemic immune response, possibly due to the translocation of LPS from the digestive tract (Khafipour et al., 2009a; Zebeli and Ametaj, 2009). This translocation could result from a combination of a high LPS concentration in the rumen and a compromised barrier function of the ruminal epithelium (Kleen et al., 2003; Chin et al., 2006; Khafipour et al., 2009a). Recent findings also suggest that high grain diets and SARA may be associated with increased permeability of the rumen epithelium through reduced organization and thickness of this epithelium, even in the absence of visible tissue damage (Steele et al., 2011).

Using 2 feeding protocols to induce SARA, Khafipour et al. (2009b) found that rumen $\mathrm{pH}$ depression and increase in LPS concentration in the rumen were similar in cows on feeding regimens in which either 
pelleted ground alfalfa or wheat-barley pellets were used to induce SARA. However, in contrast to the alfalfa-pellet SARA challenge, the grain-based SARA challenge resulted in elevated levels of acute phase proteins in peripheral blood. These results suggest that the combination of low $\mathrm{pH}$ and high LPS concentration in the rumen alone may not cause translocation of LPS. A possible explanation for the different response between grain-based and alfalfa-pellet SARA challenges could be the amount of starch that is fermented in the large intestine. High levels of intake of starch increase fermentation in the large intestine (Reynolds, 2006). Therefore, it is possible that only the grain-based SARA challenge increased fermentation and LPS production in the large intestine. In view of the results from the study by Khafipour et al. (2009a), we hypothesized that, despite creating similar conditions of $\mathrm{pH}$ and LPS concentration within the rumen, conditions in the large intestine differ between alfalfa pellet- and grain-based SARA challenges. We further postulate that these differences in the large intestine affect the translocation of LPS into the systemic circulation.

\section{MATERIALS AND METHODS}

\section{Animals, Diets, and Experimental Procedures}

Six nonlactating, multiparous Holstein cows with average initial BW of $620 \pm 45.7 \mathrm{~kg}($ mean $\pm \mathrm{SD})$ that were cannulated in the rumen and cecum were used. A $3 \times 3$ Latin square arrangement of treatments with 4-wk experimental periods was adopted. Cecal cannulas were T-shaped and consisted of a barrel and a crosspiece. The barrel was $170 \mathrm{~mm}$ long and had an external diameter of $35 \mathrm{~mm}$. The crosspiece had an external diameter of $55 \mathrm{~mm}$ and was cut into an oval with a large diameter of $90 \mathrm{~mm}$ and a small diameter of $50 \mathrm{~mm}$. All cecal cannulas were made of plastisol (FH and Sons Manufacturing Ltd., Rexdale, ON, Canada). The cannulation procedure was adapted from MacRae et al. (1973), and the cecal cannulas were placed in the middle of the cecum. The site of exit of the cecal cannula was located at approximately 200 to $250 \mathrm{~mm}$ below the hook bone and 120 to $150 \mathrm{~mm}$ after the last rib to maintain the normal distribution and movement of the cecal digesta.

Experimental periods consisted of 4 wk in which all cows received a diet containing $70 \%$ (DM basis) forage (Table 1) in the first 3 wk. Ingredient and nutrient composition of experimental diets are presented in Table 1, and nutrient composition of individual ingredients used to make these diets is presented in Table 2. During wk 4, cows received 1 of 3 diets: the $70 \%$ forage diet (control), a diet in which $34 \%$ of DM was replaced with grain pellets made of $50 \%$ ground wheat and 50\% ground barley (designated the grain-based SARA challenge, GBSC), and a diet in which $37 \%$ of DM was replaced with pellets made of ground alfalfa (designated the alfalfa-pellet SARA challenge, APSC; Table 1). Cows were housed in individual stalls in the large animal metabolism facility of the Glenlea Research Station, University of Manitoba, and were cared for in accordance with the Canadian Council for Animal Care guidelines (CCAC, 1993). Cows were fed ad libitum once daily at $0900 \mathrm{~h}$, allowing for between 5 and $10 \%$ of feed refusals, and had unlimited access to fresh water. During wk 4 of all experimental periods, rumen $\mathrm{pH}$ was measured continuously from d 2 to d 5 , and DMI was determined daily in all cows. Blood, feces, rumen, and cecal contents were sampled immediately before feed delivery and at $6 \mathrm{~h}$ after feed delivery on $\mathrm{d} 3$ and 5 .

\section{DMI and Feed Analyses}

The amounts of TMR offered and refused were recorded daily for each cow. Diet samples were collected twice weekly and individual ort samples were collected daily during collection periods. Individual feeds were sampled once per collection period. Diets, feed, and orts samples were pooled across collection periods. Orts of individual cows were pooled by weight. The DM content of pooled diets, forages, and ort samples were determined by drying at $60^{\circ} \mathrm{C}$ for $48 \mathrm{~h}$ in a forced air oven. Dried feed samples were ground using a Wiley mill through a 1-mm screen (Thomas-Wiley, Philadelphia, PA) and stored at $-20^{\circ} \mathrm{C}$ until analyzed by wet chemistry as described by Bhandari et al. (2007). The starch contents of diet and feed samples were determined using an enzymatic technique (AOAC, 1990; method 996.11).

\section{Rumen Sampling and Analyses}

Rumen $\mathrm{pH}$ was monitored continuously using indwelling $\mathrm{pH}$ probes as described by Gozho et al. (2005). The $\mathrm{pH}$ data were summarized as average $\mathrm{pH}$, times below $\mathrm{pH}$ thresholds of $6.0,5.8$, and 5.6, and areas (time $\times$ $\mathrm{pH})$ below $\mathrm{pH}$ thresholds of $6.0,5.8$, and 5.6 for each 24-h period.

Ruminal contents were collected from the ventral sac of the rumen and strained through 4 layers of sterile cheesecloth. The rumen fluid was collected and divided into 2 portions. The first portion of each sample was transferred into a 50-mL sterile tube and kept on ice until transported to the laboratory for the initial processing before LPS determination as described by Gozho et al. (2005). Briefly, rumen fluid samples were centrifuged at $10,000 \times g$ for $45 \mathrm{~min}$ at $4^{\circ} \mathrm{C}$ and the 
LI ET AL.

Table 1. Ingredients and nutrient composition of the control diet and the diets fed during the alfalfa-pellet subacute ruminal acidosis (SARA) challenge (APSC) and the grain-based SARA challenge (GBSC)

\begin{tabular}{|c|c|c|c|}
\hline Item & Control & APSC & GBSC \\
\hline \multicolumn{4}{|l|}{ Ingredients, $\%$ of DM } \\
\hline Barley silage & 40 & 33 & 28 \\
\hline Alfalfa hay & 30 & - & 8 \\
\hline Supplement & 30 & 30 & 30 \\
\hline Wheat-barley pellets & - & - & 34 \\
\hline Alfalfa pellets & - & 37 & - \\
\hline \multicolumn{4}{|l|}{ Nutrient composition } \\
\hline DM, \% & 54.3 & 69.0 & 61.6 \\
\hline $\mathrm{CP}, \%$ of $\mathrm{DM}$ & 16.1 & 16.0 & 16.0 \\
\hline $\mathrm{NDF}, \%$ of DM & 35.6 & 34.5 & 22.9 \\
\hline $\mathrm{ADF}, \%$ of DM & 23.3 & 22.6 & 15.2 \\
\hline $\mathrm{NFC},{ }^{1} \%$ of DM & 34.8 & 49.0 & 50.4 \\
\hline Starch, $\%$ of DM & 14.2 & 15.9 & 33.7 \\
\hline Crude fat, $\%$ of DM & 3.6 & 3.2 & 3.3 \\
\hline Ash, \% of DM & 9.9 & 7.3 & 7.4 \\
\hline $\mathrm{Ca}, \%$ of DM & 0.85 & 0.13 & 0.64 \\
\hline $\mathrm{P}, \%$ of $\mathrm{DM}$ & 0.35 & 0.35 & 0.41 \\
\hline $\mathrm{Mg}, \%$ of $\mathrm{DM}$ & 0.35 & 0.30 & 0.29 \\
\hline $\mathrm{K}, \%$ of $\mathrm{DM}$ & 0.21 & 0.18 & 1.25 \\
\hline $\mathrm{Na}, \%$ of $\mathrm{DM}$ & 0.27 & 0.32 & 0.28 \\
\hline
\end{tabular}

supernatant was aspirated gently to prevent its mixing with the pellet and passed through a disposable $0.22-$ $\mu \mathrm{m}$ LPS-free filter (Millex, Millipore Corp., Bedford, MA). The filtrate was collected in a sterile, depyrogenated glass tube (previously heated at $180^{\circ} \mathrm{C}$ for $4 \mathrm{~h}$ ) and heated at $100^{\circ} \mathrm{C}$ for $30 \mathrm{~min}$. Samples were cooled at room temperature $\left(19^{\circ} \mathrm{C}\right)$ for $10 \mathrm{~min}$ and stored at $-20^{\circ} \mathrm{C}$ for subsequent LPS analysis. The second portion of each rumen fluid sample was centrifuged at $3,000 \times g$ for $15 \mathrm{~min}$ at $4^{\circ} \mathrm{C}$ immediately after collection and the supernatant was aliquoted into 2 vials for ammonia nitrogen and VFA analyses. Samples for ammonia nitrogen analysis were acidified with $1 \mathrm{M} \mathrm{HCl}$ to inhibit microbial activity and minimize volatilization of ammonia nitrogen. Samples for VFA analysis had $1 \mathrm{~mL}$ of $25 \%$ meta-phosphoric acid added to $5 \mathrm{~mL}$ of rumen fluid to deproteinize the sample. These samples were stored at $-20^{\circ} \mathrm{C}$ until analysis.

Free LPS in rumen fluid was measured by a chromogenic kinetic Limulus amebocyte lysate assay (Kinetic-QCL, Lonza Group Ltd., Basel, Switzerland) in a 96-well microplate using an incubating microplate spectrophotometer (Spectra Max 340 PC, Molecular Devices Corp., Sunnyvale, CA) as described by Khafipour et al. (2009a). Rumen fluid samples were diluted 1:100,000, with the final dilution being made of $50 \%$ diluted sample and $50 \%$ $\beta$-glucan blocker (cat. no. N190, Lonza Group Ltd.).

Concentrations of VFA were determined by gas chromatography (model 3900 Star, Varian, Walnut Creek, CA) as described by Bhandari et al. (2007). Briefly, rumen fluid samples were thawed at room temperature,

Table 2. Nutrient composition (\% of DM unless otherwise noted) of dietary ingredients

\begin{tabular}{|c|c|c|c|c|c|}
\hline Item & Supplement & $\begin{array}{l}\text { Barley } \\
\text { silage }\end{array}$ & $\begin{array}{l}\text { Alfalfa } \\
\text { hay }\end{array}$ & $\begin{array}{c}\text { Wheat-barley } \\
\text { pellets }\end{array}$ & $\begin{array}{l}\text { Alfalfa } \\
\text { pellets }\end{array}$ \\
\hline DM, \% & 90.5 & 39.1 & 86.0 & 87.0 & 92.2 \\
\hline $\mathrm{CP}$ & 18.4 & 8.8 & 17.2 & 144 & 15.5 \\
\hline NDF & 14.7 & 53.3 & 59.4 & 16.2 & 57.9 \\
\hline $\mathrm{ADF}$ & 7.7 & 26.9 & 34.1 & 7.8 & 29.6 \\
\hline $\mathrm{NFC}^{1}$ & 56.3 & 26.7 & 13.3 & 61.9 & 17.9 \\
\hline Starch & 35.6 & 19.5 & 0.9 & 48.7 & 1.5 \\
\hline Crude fat & 3.9 & 2.9 & 2.3 & 3.2 & 2.1 \\
\hline Ash & 6.7 & 8.3 & 7.8 & 4.3 & 6.6 \\
\hline $\mathrm{Ca}$ & 1.05 & 0.48 & 1.04 & 0.55 & 2.81 \\
\hline $\mathrm{P}$ & 0.67 & 0.29 & 0.08 & 0.47 & 0.14 \\
\hline K & 0.80 & 1.69 & 1.73 & 0.19 & 1.54 \\
\hline $\mathrm{Mg}$ & 0.50 & 0.20 & 0.10 & 0.19 & 0.32 \\
\hline $\mathrm{Na}$ & 0.53 & 0.17 & 0.05 & 0.35 & 0.14 \\
\hline
\end{tabular}


and $0.4 \mathrm{~mL}$ of $25 \%$ sodium hydroxide and $0.64 \mathrm{~mL}$ of $0.3 M$ oxalic acid were added to the tubes and vortexed. The tubes were centrifuged at $3,000 \times g$ for $20 \mathrm{~min}$, and $2 \mathrm{~mL}$ of supernatant was transferred into vials for VFA analysis. Ammonia nitrogen concentration of rumen fluid samples was determined using a colorimetric technique as described by Bhandari et al. (2007).

\section{Fecal and Cecal Sampling and Analyses}

Fecal samples were collected per rectum, and cecal samples were collected via the cecal cannula. A subsample of $10 \mathrm{~g}$ of feces was mixed with $5 \mathrm{~mL}$ of distilled water for measurement of fecal $\mathrm{pH}$. The $\mathrm{pH}$ of diluted fecal samples and cecal digesta samples were determined immediately after sampling using an Accumet Basic $15 \mathrm{pH}$ meter and an Accumet gel-filled, polymer body combination $\mathrm{pH}$ electrode (Fisher Scientific, Fairlawn, NJ). Fecal samples were also examined for the presence of mucin casts. Both fecal and cecal samples were divided into 3 portions. One portion of each of these samples was mixed thoroughly with an equal amount of physiological saline $(0.90 \% \mathrm{wt} / \mathrm{vol}$ of $\mathrm{NaCl}$ ). The mixtures were immediately centrifuged at $3,000 \times g$ for $15 \mathrm{~min}$ and the supernatants were stored at $-20^{\circ} \mathrm{C}$ until analyzed for VFA and ammonia nitrogen using the same method described earlier for rumen fluid. The second portion of each of the cecal and fecal samples was processed for LPS analyses using a method adapted from Rogers et al. (1985), in which $10 \mathrm{~g}$ of sample was transferred into a pyrogen-free tube with $10 \mathrm{~mL}$ of physiological saline and mixed vigorously. Samples were then processed and analyzed for LPS using the same procedure described earlier for rumen fluid samples. The LPS concentration in cecal and fecal samples was expressed as endotoxin units (EU) per gram of wet sample. The third portion of each of the fecal and cecal samples was dried at $60^{\circ} \mathrm{C}$ for $48 \mathrm{~h}$. Dried samples were subsequently ground using a Wiley mill through a 1-mm screen (Thomas-Wiley, Philadelphia, PA) and stored at $-20^{\circ} \mathrm{C}$ until analyzed for starch using a Megazyme Total Starch assay kit (Megazyme International Ireland Ltd., Bray, Ireland).

\section{Blood Sampling and Analyses}

Blood samples were taken from the coccygeal vein as described by Gozho et al. (2005). Plasma was harvested by centrifuging blood samples in heparinized Vacutainers (Fisher Scientific) at 3,000 $\times g$ for $15 \mathrm{~min}$. A portion of plasma was transferred to pyrogen-free glass tubes and stored at $-20^{\circ} \mathrm{C}$ for LPS analysis. The rest of the plasma was divided into $2-\mathrm{mL}$ aliquots and stored at $-20^{\circ} \mathrm{C}$ until analyzed for LPS-binding protein (LBP). Plasma concentrations of LBP were measured using a commercially available kit (HK503, HyCult Biotechnology, Uden, the Netherlands) using a microplate spectrophotometer (Spectra Max 340 PC, Molecular Devices Corp.). The concentration of LPS in plasma was determined by a chromogenic kinetic Limulus amebocyte lysate assay (Kinetic-QCL, Lonza Group Ltd.) as described by Khafipour et al. (2009a).

\section{Statistical Analyses}

Data were analyzed using the MIXED procedure of SAS (2003; SAS Institute Inc., Cary, NC). The models for daily DMI and summarized rumen $\mathrm{pH}$ data included fixed effects of treatment (control, GBSC, or APSC), period, day, and their interactions. Cow was considered a random effect in the model. The models used for VFA, LBP, and LPS also included the fixed effects of time and the interactions of time with the other fixed factors. Day was considered a repeated measure. Normality of distributions of residuals was tested using Proc UNIVARIATE of SAS (SAS Institute Inc.). If necessary, data were transformed to alleviate heterogeneity of residual variances. Fixed effects were considered significant at $P<0.05$, and trends were discussed at $P<0.10$.

\section{RESULTS}

\section{Diets and DMI}

Because of the higher inclusion rates of pellets, diets used for the SARA challenges contained more DM than the control diet (Table 1). The CP content did not differ among experimental diets. The NDF contents of the control and APSC diets were similar, but higher than that of the GBSC diet. The starch content of the diet used for GBSC was much higher than that of the control diet and the APSC diet. Both SARA challenges increased DMI compared with the control, but DMI did not differ between the 2 SARA challenges (Table 3 ).

\section{$p H, V F A$, and LPS in Rumen Fluid}

Both SARA challenges reduced the average daily rumen $\mathrm{pH}$ and increased the daily time of the rumen $\mathrm{pH}$ below 6.0, 5.8, and 5.6, as well as increased the daily area below pH 6.0, 5.8 and 5.6 (Table 3). Day affected the duration of the rumen $\mathrm{pH}$ below 5.6 and the area of rumen $\mathrm{pH}$ below 6.0, 5.8, and 5.6, and tended to affect the average daily $\mathrm{pH}$. These measures of the rumen $\mathrm{pH}$ indicated a less severe rumen $\mathrm{pH}$ depression during 
Table 3. Rumen $\mathrm{pH}$ variables and DMI of dairy cows fed a control diet or given an alfalfa-pellet subacute ruminal acidosis (SARA) challenge (APSC) or a grain-based SARA challenge (GBSC)

\begin{tabular}{|c|c|c|c|c|c|c|c|}
\hline \multirow[b]{2}{*}{ Item } & \multicolumn{3}{|c|}{ Treatment } & \multirow[b]{2}{*}{$\mathrm{SED}^{1}$} & \multicolumn{3}{|c|}{ Effect, $P$-value } \\
\hline & Control & APSC & GPSC & & Treatment & Day & $\begin{array}{l}\text { Treatment } \\
\times \text { day }\end{array}$ \\
\hline $\mathrm{DMI}, \mathrm{kg} / \mathrm{d}$ & $15.4^{\mathrm{b}}$ & $16.7^{\mathrm{a}}$ & $17.6^{\mathrm{a}}$ & 0.06 & 0.02 & 0.98 & 0.63 \\
\hline Average $\mathrm{pH}$ & $6.30^{\mathrm{a}}$ & $5.99^{\mathrm{b}}$ & $5.98^{\mathrm{b}}$ & 0.04 & $<0.001$ & 0.08 & 0.21 \\
\hline Time $<\mathrm{pH} 5.6, \mathrm{~min} / \mathrm{d}$ & $56.4^{\mathrm{b}}$ & $255.2^{\mathrm{a}}$ & $298.7^{\mathrm{a}}$ & 30.7 & $<0.001$ & 0.04 & 0.35 \\
\hline Time $<\mathrm{pH} 5.8 . \mathrm{min} / \mathrm{d}$ & $188.1^{\mathrm{b}}$ & $488.5^{\mathrm{a}}$ & $514.0^{\mathrm{a}}$ & 53.5 & $<0.001$ & 0.32 & 0.11 \\
\hline Time $<\mathrm{pH} 6.0, \mathrm{~min} / \mathrm{d}$ & $331.5^{\mathrm{b}}$ & $770.1^{\mathrm{a}}$ & $743.8^{\mathrm{a}}$ & 57.6 & $<0.001$ & 0.27 & 0.17 \\
\hline Area $<\mathrm{pH} 5.6, \min \times \mathrm{pH} / \mathrm{d}$ & $4.96^{\mathrm{b}}$ & $35.00^{\mathrm{a}}$ & $53.20^{\mathrm{a}}$ & 6.5 & $<0.001$ & 0.04 & 0.24 \\
\hline Area $<\mathrm{pH} 5.8, \min \times \mathrm{pH} / \mathrm{d}$ & $27.7^{\mathrm{c}}$ & $106.7^{\mathrm{b}}$ & $133.1^{\mathrm{a}}$ & 16.8 & $<0.001$ & 0.05 & 0.12 \\
\hline Area $<\mathrm{pH} 6.0, \min \times \mathrm{pH} / \mathrm{d}$ & $78.7^{\mathrm{b}}$ & $229.6^{\mathrm{a}}$ & $257.8^{\mathrm{a}}$ & 33.5 & $<0.001$ & 0.04 & 0.17 \\
\hline
\end{tabular}

$\overline{\mathrm{a}, \mathrm{b}}$ Means with different superscripts within a row are different $(P<0.05)$.

${ }^{1} \mathrm{SED}=$ standard error of difference between treatments.

the second and third day than during the other days of these SARA challenges. The interaction between day and treatment did not affect any of the rumen $\mathrm{pH}$ measurements.

Subacute ruminal acidosis challenges did not affect the concentrations of total VFA, acetate, and butyrate in rumen fluid (Table 4). Both SARA challenges tended to increase the concentration of propionate and reduced the acetate to propionate ratio to the same extent. Compared with the control, GBSC increased the concentration of other VFA (isobutyrate + valerate + isovalerate) but APSC did not. The rumen fluid samples collected at $6 \mathrm{~h}$ after feed delivery had higher concentrations of total VFA (145.6 vs. 110.3 $\mathrm{m} M)$, acetate ( 89.8 vs. $70.2 \mathrm{mM})$, propionate (31.8 vs. $22.6 \mathrm{mM})$, and butyrate (17.4 vs. $12.4 \mathrm{mM}$ ) than the samples collected immediately before feed delivery. The time of sampling did not affect the concentration of other VFA or the acetate:propionate ratio. No interaction was found between treatment and time of sampling for any of the VFA concentrations. Also compared with the control, both SARA challenges increased LPS in rumen fluid, but the GBSC resulted in a larger increase than the APSC (Table 5).

\section{pH, VFA, LPS, and Starch in Cecal Digesta and Feces}

Compared with the control, daily average $\mathrm{pH}$ of cecal contents decreased in cows on both SARA challenge treatments. The SARA challenges tended to increase the concentrations of acetate and increased the concentrations of propionate, and consequently, tended to increase total VFA concentration in cecal digesta, even though concentrations of butyrate and other VFA were not affected (Table 4). The effects of both SARA challenges on the $\mathrm{pH}$ and VFA concentrations of cecal digesta were similar, but only GBSC reduced the acetate:propionate ratio in cecal digesta. Time of sampling did not affect the concentration of VFA or the acetate:propionate ratio in cecal digesta. Similarly, no treatment $x$ time interactions were found on cecal digesta VFA concentrations or the acetate:propionate ratio. The LPS concentration in cecal digesta increased in GBSC but not in APSC (Table 5).

Daily average $\mathrm{pH}$ decreased in the feces of cows in the GBSC but not in the APSC. Both SARA challenges increased the concentrations of total VFA, acetate, propionate, and butyrate in fecal samples (Table 4). Both SARA challenges had similar effects on the fecal concentrations of total VFA, acetate and propionate in fecal samples, but butyrate was higher in fecal samples of cows on GBSC than on APSC. Only GBSC reduced the acetate:propionate ratio in feces. The fecal samples collected at $6 \mathrm{~h}$ after feed delivery had lower concentrations of total VFA (63.8 vs. $69.9 \mathrm{mM} ; P<0.05)$, acetate (47.6 vs. $51.0 \mathrm{mM} ; P=0.05)$, propionate $(9.9$ vs. $10.9 \mathrm{~m} M ; P<0.05$ ), and butyrate (4.3 vs. $5.0 \mathrm{mM}$; $P<0.01)$ than those collected immediately before feed delivery. No treatment $x$ time interactions were found for VFA concentrations or acetate:propionate ratio in the feces. In feces, the LPS concentration increased when SARA was induced using GBSC but not APSC (Table 5).

Starch content of cecal digesta was higher in GBSC than in APSC and control (Table 6). However, starch content of the feces did not differ among treatments. Mucin casts were not present in feces of any of the cows throughout the experiment.

\section{LPS and LBP in Peripheral Blood Plasma}

The concentration of LPS in peripheral blood plasma was below the detection limit of the assay of $0.05 \mathrm{EU} /$ $\mathrm{mL}$ for all treatments (Table 5). Compared with the 
Table 4. Average daily composition of rumen fluid, cecal digesta, and feces of dairy cows fed a control diet or cows given an alfalfa-pellet subacute ruminal acidosis (SARA) challenge (APSC) or a grain-based SARA challenge (GBSC)

\begin{tabular}{|c|c|c|c|c|c|c|c|}
\hline \multirow[b]{2}{*}{ Item } & \multicolumn{3}{|c|}{ Treatment } & \multirow[b]{2}{*}{ SED } & \multicolumn{3}{|c|}{ Effect, $P$-value } \\
\hline & Control & APSC & GBSC & & Treatment & Time & $\begin{array}{l}\text { Treatment } \\
\times \text { time }\end{array}$ \\
\hline \multicolumn{8}{|l|}{ Rumen fluid } \\
\hline Total VFA, mM & 118.2 & 138.3 & 127.3 & 11.4 & 0.26 & $<0.0001$ & 0.16 \\
\hline Acetate, $\mathrm{m} M$ & 78.9 & 86.2 & 74.9 & 6.9 & 0.30 & $<0.0001$ & 0.21 \\
\hline Propionate, $\mathrm{m} M$ & $21.0^{\mathrm{x}}$ & $30.2^{\mathrm{y}}$ & $30.3^{\mathrm{y}}$ & 4.0 & 0.09 & $<0.0001$ & 0.17 \\
\hline Butyrate, $\mathrm{m} M$ & 13.0 & 17.0 & 15.4 & 2.3 & 0.26 & $<0.0001$ & 0.13 \\
\hline Other, ${ }^{2} \mathrm{~m} M$ & $5.3^{\mathrm{b}}$ & $5.0^{\mathrm{b}}$ & $6.6^{\mathrm{a}}$ & 0.3 & $<0.0001$ & 0.001 & 0.08 \\
\hline $\mathrm{Ac}: \mathrm{Pr}^{3}$ & $3.8^{\mathrm{a}}$ & $3.1^{\mathrm{a}}$ & $2.7^{\mathrm{b}}$ & 0.4 & 0.04 & 0.001 & 0.68 \\
\hline Ammonia-N, mg/dL & 8.4 & 8.5 & 11.1 & 1.6 & 0.16 & 0.54 & 0.34 \\
\hline \multicolumn{8}{|l|}{ Cecal digesta } \\
\hline $\mathrm{pH}$ & $7.07^{\mathrm{a}}$ & $6.86^{\mathrm{b}}$ & $6.79^{\mathrm{b}}$ & 0.1 & 0.05 & $<0.01$ & 0.89 \\
\hline Total VFA m $M$ & $92.0^{\mathrm{y}}$ & $116.8^{\mathrm{x}}$ & $126.6^{\mathrm{x}}$ & 11.9 & 0.09 & 0.47 & 0.31 \\
\hline Acetate, $\mathrm{m} M$ & $64.3^{\mathrm{y}}$ & $84.3^{\mathrm{x}}$ & $91.6^{\mathrm{x}}$ & 8.4 & 0.06 & 0.32 & 0.29 \\
\hline Propionate, $\mathrm{m} M$ & $13.1^{\mathrm{b}}$ & $15.4^{\mathrm{b}}$ & $18.1^{\mathrm{a}}$ & 1.4 & 0.05 & 0.98 & 0.21 \\
\hline Butyrate, $\mathrm{m} M$ & 6.9 & 8.7 & 9.2 & 1.5 & 0.34 & 0.61 & 0.53 \\
\hline Other, $\mathrm{m} M$ & 6.7 & 8.4 & 7.7 & 1.8 & 0.69 & 0.95 & 0.59 \\
\hline $\mathrm{Ac}: \operatorname{Pr}$ & 5.2 & 5.5 & 5.1 & 0.3 & 0.39 & 0.20 & 0.88 \\
\hline Ammonia-N, mg/100 g of wet digesta & 47.0 & 35.2 & 25.7 & 9.3 & 0.11 & 0.36 & 0.43 \\
\hline \multicolumn{8}{|l|}{ Feces } \\
\hline $\mathrm{pH}$ & $6.65^{\mathrm{x}}$ & $6.61^{\mathrm{x}}$ & $6.45^{\mathrm{y}}$ & 0.06 & 0.08 & 0.07 & 0.74 \\
\hline Total VFA m $M$ & $60.9^{\mathrm{b}}$ & $69.5^{\mathrm{a}}$ & $70.2^{\mathrm{a}}$ & 3.4 & 0.02 & 0.04 & 0.33 \\
\hline Acetate, $\mathrm{m} M$ & $45.8^{\mathrm{b}}$ & $52.1^{\mathrm{a}}$ & $51.3^{\mathrm{a}}$ & 2.5 & 0.05 & 0.07 & 0.35 \\
\hline Propionate, $\mathrm{m} M$ & $9.0^{\mathrm{b}}$ & $10.7^{\mathrm{a}}$ & $11.6^{\mathrm{a}}$ & 0.6 & 0.01 & 0.04 & 0.32 \\
\hline Butyrate, $\mathrm{m} M$ & $3.9^{\mathrm{c}}$ & $4.6^{\mathrm{b}}$ & $5.3^{\mathrm{a}}$ & 0.3 & 0.01 & 0.00 & 0.65 \\
\hline Other, $\mathrm{m} M$ & 2.2 & 2.2 & 2.0 & 0.2 & 0.39 & 0.26 & 0.68 \\
\hline $\mathrm{Ac}: \operatorname{Pr}$ & $5.1^{\mathrm{x}}$ & $4.9^{\mathrm{y}}$ & $4.5^{\mathrm{y}}$ & 0.2 & 0.07 & 0.92 & 0.68 \\
\hline Ammonia-N, mg/100 g of wet feces & 10.1 & 9.6 & 11.5 & 1.6 & 0.52 & 0.99 & 0.89 \\
\hline
\end{tabular}

\footnotetext{
${ }^{\mathrm{a}-\mathrm{c}}$ Means with different superscripts within a row are different $(P<0.05)$

${ }^{\mathrm{x}, \mathrm{y}}$ Means with different superscripts within a row are different $(P<0.10)$.

${ }^{1} \mathrm{SED}=$ standard error of difference between treatments.

${ }^{2}$ Other $=$ isobutyrate + valerate + isovalerate.

${ }^{3}$ Acetate to propionate ratio.
}

control, LBP in peripheral blood plasma increased in cows on the GBSC but not in those on the APSC (Table 5).

\section{DISCUSSION}

Our objective was to conduct SARA challenges that resulted in similar rumen $\mathrm{pH}$ depressions but that differed in the starch content of rumen and hind gut digesta. Several rumen $\mathrm{pH}$ thresholds (e.g., 6.0, 5.8, 5.6, and 5.5) have been used to define SARA (Kleen et al., 2003; Krause and Oetzel, 2005; Plaizier et al., 2008). Gozho et al. (2005) defined SARA as a rumen $\mathrm{pH}$ depression below 5.6 for more than $180 \mathrm{~min} / \mathrm{d}$, as only such a rumen $\mathrm{pH}$ depression increased the concentrations of acute phase proteins in peripheral blood and LPS in rumen fluid. Based on this definition, both SARA challenges were successful in inducing SARA. Both SARA challenges resulted in similar rumen $\mathrm{pH}$ depressions and similar reductions of the $\mathrm{pH}$ of cecal digesta. The rumen $\mathrm{pH}$ depression in the GBSC was similar to that obtained in the grain-based SARA chal- lenge conducted by Khafipour et al. (2009a), whereas the rumen $\mathrm{pH}$ depression in the APSC was lower than that obtained in the alfalfa-pellet SARA challenge conducted by Khafipour et al. (2009b; 255 vs. $510 \mathrm{~min} / \mathrm{d}$ below $\mathrm{pH}$ 5.6). The rumen $\mathrm{pH}$ depressions obtained in the SARA challenges in our study were comparable to those obtained by the grain-based SARA challenges of Dohme et al. (2008) for cows with a low risk of SARA and that of Gozho et al. (2007). However, in our study the SARA challenges resulted in rumen $\mathrm{pH}$ depressions that were lower than those caused by the grain-based SARA challenges in cows with a high risk of SARA conducted by Dohme et al. (2008; average of $10.6 \mathrm{~h} / \mathrm{d}$ below $\mathrm{pH} 5.8$ ) and the grain-based SARA challenge conducted by Krause and Oetzel (2005; 8.26 h/d below $\mathrm{pH}$ 5.6). These comparisons among studies suggest that the episodes of SARA in our study were not severe. This is also supported by increases, rather than decreases, in DMI in these challenges. The rumen $\mathrm{pH}$ depression as a result of these SARA challenges was not accompanied by increases in total VFA in the rumen. This was unexpected, in view of reports from other studies (Goad et 
Table 5. Concentrations of free LPS in wet digesta in the rumen and in the cecum, in wet feces, and in blood plasma, and the concentration of LPS binding protein (LBP) in blood plasma of dairy cows fed a control diet or cows given an alfalfa-pellet subacute ruminal acidosis (SARA) challenge (APSC) or a grain-based SARA challenge (GBSC)

\begin{tabular}{|c|c|c|c|c|c|c|c|}
\hline \multirow[b]{2}{*}{ Item } & \multicolumn{3}{|c|}{ Treatment } & \multirow[b]{2}{*}{$\mathrm{SED}^{1}$} & \multicolumn{3}{|c|}{ Effect, $P$-value } \\
\hline & Control & APSC & GBSC & & Treatment & Time & $\begin{array}{l}\text { Treatment } \\
\times \text { time }\end{array}$ \\
\hline \multicolumn{8}{|l|}{ Rumen fluid } \\
\hline $\mathrm{LPS}, \mathrm{EU}^{2} / \mathrm{mL}$ & $10,405^{\mathrm{c}}$ & $30,715^{\mathrm{b}}$ & $168,391^{\mathrm{a}}$ & 8,738 & $<0.01$ & 0.84 & 0.72 \\
\hline \multicolumn{8}{|l|}{ Cecal digesta } \\
\hline LPS, EU/g of wet digesta & $16,508^{\mathrm{b}}$ & $14,458^{\mathrm{b}}$ & $118,522^{\mathrm{a}}$ & 24,057 & $<0.001$ & 0.81 & 0.78 \\
\hline \multicolumn{8}{|l|}{ Feces } \\
\hline LPS, EU/g of wet feces & $12,832^{\mathrm{b}}$ & $17,326^{\mathrm{b}}$ & $93,154^{\mathrm{a}}$ & 14,216 & 0.05 & 0.14 & 0.64 \\
\hline \multicolumn{8}{|l|}{ Blood plasma } \\
\hline LPS, EU/mL & $<0.05$ & $<0.05$ & $<0.05$ & $\mathrm{ND}^{3}$ & ND & ND & ND \\
\hline $\mathrm{LBP}, \mathrm{mg} / \mathrm{L}^{4}$ & $8.9^{\mathrm{b}}$ & $9.5^{\mathrm{b}}$ & $12.1^{\mathrm{a}}$ & 1.3 & 0.05 & 0.29 & 0.89 \\
\hline \multicolumn{8}{|c|}{$\overline{\mathrm{a}, \mathrm{b}}$ Means with different superscripts within a row are different $(P<0.05)$. } \\
\hline \multicolumn{8}{|c|}{${ }^{1} \mathrm{SED}=$ standard error of difference between treatments. } \\
\hline \multicolumn{8}{|l|}{${ }^{2} \mathrm{EU}=$ endotoxin unit. } \\
\hline \multicolumn{8}{|l|}{${ }^{3} \mathrm{ND}=$ not determined. } \\
\hline${ }^{4}$ Source: Kroeker et al. $(2010$ & & & & & & & \\
\hline
\end{tabular}

al., 1998; Khafipour et al., 2009a,b), but could be the result of the more frequent rumen $\mathrm{pH}$ measurements compared with the rumen VFA measurements.

Siciliano-Jones and Murphy (1989) fed diets with forage to concentrate ratios ranging from 20:80 to 80:20 to steers and observed cecal $\mathrm{pH}$ values of 5.80 and 6.68 for the high and low concentrate diets, respectively. Despite this variation, the forage to concentrate ratio did not affect cecal $\mathrm{pH}$ significantly in their study. The cecal $\mathrm{pH}$ in both SARA challenges in the current study were comparable to those observed by Siciliano-Jones and Murphy (1989) in steers on high concentrate diets, but higher than that in steers on low forage diets. This could be expected, because the diets used in both SARA challenges in our study contained more forage than the low forage diets used by Siciliano-Jones and Murphy (1989). In a recent study, Bissell and Hall (2010) infused $4 \mathrm{~kg}$ of corn starch daily into the abomasum of nonlactating dairy cows. Those authors observed a decline in fecal pH from 6.9 to between 4.9 and 5.1. Based on these $\mathrm{pH}$ values, they concluded that hindgut acidosis was induced. These fecal $\mathrm{pH}$ values were much lower than the fecal $\mathrm{pH}$ values in the SARA challenges in our study. Gressley et al. (2011) noted that hindgut acidosis is characterized by the appearance of mucin casts in the feces. Mucin casts were not found in any of the SARA challenges in our study. Hence, the SARA challenges used in our study did not induce clinical hindgut acidosis.

Goad et al. (1998) concluded that the decrease in rumen $\mathrm{pH}$ in SARA is due to increases in total VFA. In agreement with this, Khafipour et al. (2009a,b) observed that SARA challenges were associated with increases in the concentration of total VFA in rumen fluid. Despite this, the SARA challenges did not affect the concentration of total VFA in our experiment, although a trend was observed toward a higher rumen concentration of propionate. In agreement with the studies by Gozho et al. (2007), Khafipour et al. (2009a), and Khafipour et al. (2009b), SARA challenges in our study decreased the acetate to propionate ratio.

The increase in starch in cecal digesta due to the GBSC treatment agrees with many earlier studies that showed that increasing the dietary starch content increases the proportion of the ingested starch that bypasses fermentation in the rumen and digestion in the

Table 6. Starch content of cecal digesta of dairy cows fed a control diet or cows given an alfalfa-pellet subacute ruminal acidosis (SARA) challenge (APSC) or a grain-based SARA challenge (GBSC)

\begin{tabular}{lccccc}
\hline & \multicolumn{3}{c}{ Treatment } & & Effect, $P$-value \\
\cline { 2 - 4 } $\begin{array}{l}\text { Starch content, } \\
\text { \% of DM }\end{array}$ & Control & APSC & GBSC & SED $^{1}$ & Treatment \\
\hline Cecal digesta & $2.8^{\mathrm{b}}$ & $2.6^{\mathrm{b}}$ & $7.4^{\mathrm{a}}$ & 1.2 & 0.04 \\
Feces & 4.2 & 3.9 & 6.1 & 1.8 & 0.22 \\
\hline
\end{tabular}

${ }^{\mathrm{a}, \mathrm{b}}$ Means with different superscripts within a row are different $(P<0.05)$.

${ }^{1} \mathrm{SED}=$ standard error of difference between treatments. 
small intestine (Owens et al., 1986; Huntington, 1997; Reynolds, 2006). The reduction of the $\mathrm{pH}$ and the increases in the total VFA content of cecal digesta suggest that both SARA challenges resulted in increased fermentation in the large intestine. The increase in starch content of the cecal digesta, which only occurred in GBSC, indicates that only the GBSC caused increased fermentation of starch in the hindgut. Increased fermentation in the large intestine and an increase in the concentration of total VFA in cecal digesta resulting from feeding more grain-based concentrate were also observed by Siciliano-Jones and Murphy (1989). The increase in fermentation in the large intestine due to the APSC may be explained by a higher passage rate of feed particles through the rumen, which can also increase postruminal fermentation (Soita et al., 2003).

The increase in rumen LPS concentration due to increased starch feeding is well documented (Motoi et al., 1993; Emmanuel et al., 2008; Zebeli and Ametaj, 2009). Hence, the increases in rumen LPS concentration resulting from the grain-based SARA challenges conducted by Gozho et al. (2007) and Khafipour et al. (2009a), as well as from the GBSC conducted in our study, were expected. However, the increase in rumen LPS concentration in the APSC in our study was lower than that obtained in the alfalfa-pellet SARA challenge conducted by Khafipour et al. (2009b). This may be explained by the lower rumen $\mathrm{pH}$ observed in the alfalfa-pellet SARA challenge of Khafipour et al. (2009b) compared with that obtained in the APSC in our study. This difference may have resulted in a comparatively higher lysis of gram-negative bacteria in the SARA challenge of Khafipour et al. (2009b) compared with our study. In addition, Khafipour et al. (2009b) fed alfalfa pellets at increasing dietary inclusion rates in a 4-wk period, whereas in our study these pellets were only fed for $1 \mathrm{wk}$ in each experimental period. As a result, the microbial populations in the digestive tract in the study from Khafipour et al. (2009b) had a longer time to adapt to the alfalfa pellets compared with these populations in our study. This difference in adaptation time between these studies could have caused differences in the populations of gram-negative bacteria in the rumen.

Bertok (2004) concluded that bile acids cause degradation of LPS in the small intestine. In addition, Ribeiro et al. (2010) concluded that the acidic conditions in the abomasum also deactivate LPS. Hence, it can be expected that the increase in LPS concentration in the cecum in grain-based SARA challenges are due to increased growth of LPS-producing bacteria in the hind gut but not in the rumen. In support of this, Van Kessel et al. (2002) observed that postruminal infusion of starch increased the concentration of gram-negative bacteria, including coliform bacteria, in cecal digesta. The lack of an influx of the starch to the large intestine in cows in APSC may explain why, despite a similar decrease in the $\mathrm{pH}$ and increase in the concentration of total VFA in cecal digesta than those in the GBSC, the APSC did not increase the cecal LPS concentration. As the indigestible part of digesta in the large intestine is not acidified or mixed with bile acids before it becomes part of the feces, the LPS in the feces most likely originated in the large intestine. This explains why the concentrations of LPS in feces mirrored those in cecal digesta in the current study.

Similar to the study of Khafipour et al. (2009b), the APSC in the current study did not increase the concentration of LPS in peripheral blood. In contrast to the studies of Andersen et al. (1994) and Khafipour et al. (2009a), GBSC in our study also did not increase the concentration of LPS in peripheral blood. In agreement with our study, Andersen and Jarlov (1990) and Gozho et al. (2007) observed that grain-based SARA challenges did not increase LPS in peripheral blood. However, in the study of Gozho et al. (2007), this may have been due the poor sensitivity of the assay used for measurement of LPS in this study. Under normal physiological conditions in the rumen, its epithelium acts as a barrier that prevents the entry of LPS into the systemic circulation (Andersen et al., 1994). Stress on this epithelium, such as certain antigens and microorganisms, rapid dietary changes, and high acidity, LPS concentration, and osmolality of the digesta, can reduce the barrier function and increase epithelial permeability, resulting in systemic uptake of LPS (Owens et al., 1998; Chin et al., 2006; Steele et al., 2009). The SARA challenges could provide a stress on the epithelium by increasing the acidity and the LPS concentration of digesta. In contrast to those in the study of Khafipour et al. (2009a), cows used in our study were not lactating and may have experienced less stress compared with those used in the former study. Lactation can pose a stress on the cows, and this may explain why, in contrast to our study, Khafipour et al. (2009a) observed that the grain-based SARA challenge was associated with an increase in LPS concentration in peripheral blood.

The difference in the microbiome of the hindgut digesta between the GBSC and the APSC (due to the higher starch content of this digesta in the GBSC) most likely contributed to the difference in acute phase response between these SARA challenges. The increase in E. coli in the hindgut that is expected to have occurred in the GBSC (Van Kessel et al., 2002; Callaway et al., 2009) increases the production of LPS from Escherichia coli in the hind gut. This LPS is more potent than the LPS of most gram-negative bacteria (Sones- 
son et al., 1994). In support of this, a parallel study showed that GBSC lead to a larger increase in E. coli in the cecum compared with APSC (Li et al., 2011). The epithelium of the large intestine has a monolayer structure, whereas that of the rumen has a multilayered structure with tight junctions in the 2 middle layers (Graham and Simmons, 2005). Histological differences between the rumen and the large intestine may imply that the barrier function of the epithelium of the large intestine is more easily compromised by high acidity and high LPS concentration than that of the rumen. The increase in the concentration of LPS in the cecum, combined with an increase in the toxicity of this LPS, in a grain-based SARA challenge, therefore, creates a health risk for cows that is not present in an alfalfapellet SARA challenge.

Andersen and Jarlov (1990) concluded that endotoxemia can occur even when LPS is not present in peripheral blood, as the clearance rate of the LPS in the Kupfer cells of the liver is very high (Andersen and Jarlov, 1990; Andersen et al., 1994; Satoh et al., 2008). Hence, the absence of LPS in peripheral blood in our study does not disprove that translocation of LPS occurred. Systemic LPS gives rise to an inflammation cascade that results in the production of acute phase proteins, including LBP (Tobias et al., 1988). The GBSC increased the concentration of LBP in peripheral blood plasma, whereas the APSC did not affect this LPB concentration (Kroeker et al., 2010). This increase in LBP without an accompanying increase in LPS in peripheral blood in the GBSC, therefore, provides evidence that this challenge resulted in the translocation of LPS into the blood circulation, but that this LPS was cleared in the liver. As translocation from the rumen and translocation from the hindgut can both increase LBP, our results cannot determine where this translocation may have occurred. Hence, further research is required to determine the site of LPS translocation in grain-based SARA challenges.

The absence of an increase in LBP in the APSC provides additional evidence that this challenge did not result in translocation of LPS. It needs to be reiterated that in the studies of Gozho et al. (2007) and Khafipour et al. (2009a), the combination of a high acidity and a high LPS concentration of rumen digesta was associated with inflammation, but this does not prove that this combination was responsible for this inflammation. It also cannot be excluded that this inflammation was only localized in the rumen (Kleen et al., 2003), or that it was caused by the translocation of compounds other than LPS. Hence, translocation of LPS may be an indicator of increased permeability of the epithelium of the digestive tract, rather than the direct and sole cause of the inflammation that can accompany SARA. Further research is required to exclude this.

\section{CONCLUSIONS}

Both SARA challenges resulted in similar depressions of the $\mathrm{pH}$ of rumen and cecal digesta, but did not induce hindgut acidosis. The GBSC resulted in a greater increase in rumen LPS concentration than the APSC. Only GBSC was associated with increases in starch and LPS concentration in cecal digesta. The health risk caused by the increase in cecal LPS combined with a potentially more toxic LPS in GBSC was absent in APSC. This difference in conditions in the large intestine between the SARA challenges may explain why only GBSC was associated with inflammation. The absence of LPS in peripheral blood in GBSC may be explained by detoxification of translocated LPS before it enters the peripheral blood circulation.

\section{ACKNOWLEDGMENTS}

This study was supported by grants from Dairy Farmers of Manitoba (Winnipeg, Manitoba, Canada), the Agri-Food Research and Development Initiative (Ottawa, ON, Canada), and the Natural Sciences and Engineering Research Council of Canada (Ottawa, ON, Canada). The authors thank the staff of the Dairy Research Unit in Glenlea (University of Manitoba) for maintenance and care of the animals, and the technicians, graduate students, and postdoctoral fellows in the Department of Animal Science (University of Manitoba) for laboratory assistance and technical support during the experiment.

\section{REFERENCES}

Andersen, P. H., M. Hesselholt, and N. Jarlov. 1994. Endotoxin and arachidonic acid metabolites in portal, hepatic and arterial blood of cattle with acute ruminal acidosis. Acta Vet. Scand. 35:223-234.

Andersen, P. H., and N. Jarlov. 1990. Investigation of the possible role of endotoxin, TXA2, PGI2 and PGE2 in experimentally induced rumen acidosis in cattle. Acta Vet. Scand. 31:27-38.

AOAC. 1990. Official Methods of Analysis. 16th ed. Assoc. Off. Anal. Chem., Arlington, VA.

Bertok, L. 2004. Bile acids in physico-chemical host defense. Pathophysiology 11:139-145.

Bhandari, S. K., K. H. Ominski, K. M. Wittenberg, and J. C. Plaizier. 2007. Effects of chop length of alfalfa and corn silage on milk production and rumen fermentation of dairy cows. J. Dairy Sci. 90:2355-2366.

Bissell, H. A., and M. B. Hall. 2010. Cattle differ in ability to adapt to small intestinal digestion of starch. J. Dairy Sci. 93(E-Suppl. 1):845.

Callaway, T. R., M. A. Car, T. S. Edrington, R. C. Anderson, and D. J. Nisbet. 2009. Escherichia coli O157:H7, and cattle: A review after 10 years. Curr. Issues Mol. Biol. 11:67-79.

CCAC. 1993. Guide to the Care and Use of Experimental Animals. Vol. 1. 2nd ed. Canadian Council on Animal Care, Ottawa, ON, Canada. 
Chin, A. C., A. N. Flynn, J. P. Fedwick, and A. G. Buret. 2006. The role of caspase-3 in lipopolysaccharide-mediated disruption of intestinal epithelial tight junctions. Can. J. Physiol. Pharmacol. 84:1043-1050.

Dohme, F., T. J. DeVries, and K. A. Beauchemin. 2008. Repeated ruminal acidosis challenges in lactating dairy cows at high and low risk for developing acidosis: Ruminal pH. J. Dairy Sci. 91:35543567.

Emmanuel, D. G. V., S. M. Dunn, and B. N. Ametaj. 2008. Feeding high proportions of barley grain stimulates an inflammatory response in dairy cows. J. Dairy Sci. 91:606-614.

Goad, D. W., C. L. Goad, and T. G. Nagaraja. 1998. Ruminal microbial and fermentative changes associated with experimentally induced subacute acidosis in steers . J. Anim. Sci. 76:234-241.

Gozho, G. N., D. O. Krause, and J. C. Plaizier. 2007. Ruminal lipopolysaccharide concentration and inflammatory response during grain-induced subacute ruminal acidosis in dairy cows. J. Dairy Sci. 90:856-866.

Gozho, G. N., J. C. Plaizier, D. O. Krause, A. D. Kennedy, and K. M. Wittenberg. 2005. Subacute ruminal acidosis induces ruminal lipopolysaccharide endotoxin release and triggers an inflammatory response. J. Dairy Sci. 88:1399-1403.

Graham, C., and N. L. Simmons. 2005. Functional organization of the bovine rumen epithelium. Am. J. Physiol. Regul. Integr. Comp. Physiol. 288:R173-R181.

Gressley, T. F., M. B. Hall, and L. E. Armentano. 2011. Ruminant Nutrition Symposium: Productivity, digestion, and health responses to hindgut acidosis in ruminants. J. Anim. Sci. 89:1120-1130.

Huntington, G. B. 1997. Starch utilization by ruminants: From basics to the bunk. J. Anim. Sci. 75:852-867.

Khafipour, E., D. O. Krause, and J. C. Plaizier. 2009a. A grain-based subacute ruminal acidosis challenge causes translocation of lipopolysaccharide and triggers inflammation. J. Dairy Sci. 92:10601070.

Khafipour, E., D. O. Krause, and J. C. Plaizier. 2009b. Alfalfa pelletinduced subacute ruminal acidosis in dairy cows increases bacterial endotoxin in the rumen without causing inflammation. J. Dairy Sci. 92:1712-1724

Kleen, J. L., G. A. Hooijer, J. Rehage, and J. P. Noordhuizen. 2003 Subacute ruminal acidosis (SARA): A review. J. Vet. Med. A Physiol. Pathol. Clin. Med. 50:406-414.

Krause, K. M., and G. R. Oetzel. 2005. Inducing subacute ruminal acidosis in lactating dairy cows. J. Dairy Sci. 88:3633-3639.

Kroeker, A. D., S. Li, S. Shekhar, A. Ceballos, E. Khafipour, D. O. Krause, J. C. Plaizier, and J. C. Rodriguez-Lecompte. 2010. Characterization of immune and metabolic responses in the blood of dry cows induced with sub-acute ruminal acidosis (SARA). J. Dairy Sci. 93(E-Suppl. 1):765. (Abstr.)

Li, S., J. C. Plaizier, E. Khafipour, and D. O. Krause. 2011. Effects of subacute ruminal acidosis (SARA) challenges on bacteria in the digestive tract of dairy cows. J. Dairy Sci. 94(E-Suppl. 1):624. (Abstr.)

MacRae, J. C., C. S. W. Reid, D. W. Dellow, and R. S. Wyburn. 1973. Caecal cannulation in the sheep. Res. Vet. Sci. 14:78-85.

Motoi, Y., T. Oohashi, H. Hirose, M. Hiramatsu, S. Miyazaki, S. Nagasawa, and J. Takahashi. 1993. Turbidimetric-kinetic assay of endotoxin in rumen fluid or serum of cattle fed rations containing various levels of rolled barley. J. Vet. Med. Sci. 55:19-25.

Owens, F. N., D. S. Secrist, W. J. Hill, and D. R. Gill. 1998. Acidosis in cattle: A review. J. Anim. Sci. 76:275-286.

Owens, F. N., R. A. Zinn, and Y. K. Kim. 1986. Limits to starch digestion in the ruminant small intestine. J. Anim. Sci. 63:1634-1648.

Plaizier, J. C., D. O. Krause, G. N. Gozho, and B. W. McBride. 2008. Subacute ruminal acidosis in dairy cows: The physiological causes, incidence and consequences. Vet. J. 176:21-31.

Reynolds, C. K. 2006. Production and metabolic effects of site of starch digestion in dairy cattle. Anim. Feed Sci. Technol. 130:78-94.

Ribeiro, M. M., X. Xu, D. Klein, N. S. Kenyon, C. Ricordi, M. S. Felipe, and R. L. Pastori. 2010. Endotoxin deactivation by transient acidification. Cell Transplant. 19:1047-1054.

Rogers, M. J., R. Moore, and J. Cohen. 1985. The relationship between faecal endotoxin and faecal microflora of the C57BL mouse. J. Hyg. Camb. 95:397-402.

Satoh, M., S. Ando, T. Shinoda, and M. Yamazaki. 2008. Clearance of bacterial lipopolysaccharides and lipid A by the liver and the role of argininosuccinate synthase. Innate Immun. 14:51-60.

Siciliano-Jones, J., and M. R. Murphy. 1989. Production of volatile fatty acids in the rumen and cecum-colon of steers as affected by forage:concentrate and forage physical form. J. Dairy Sci. 72:485-492.

Soita, H. W., D. A. Christensen, and J. J. McKinnon. 2003. Effects of barley silage particle size and concentrate level on rumen kinetic parameters and fermentation patterns in steers. Can. J. Anim. Sci. 83:533-539.

Sonesson, H. R. A., U. Zähringer, H. D. Grimmecke, O. Westphal, and R. T. Rietschel. 1994. Bacterial endotoxin: Chemical structure and biological activity. Pages 1-20 in Endotoxin and the Lungs. Vol. 77. K. L. Brigham, ed. Marcel Dekker Inc., New York, NY.

Steele, M. A., O. AlZahal, S. E. Hook, J. Croom, and B. W. McBride. 2009. Ruminal acidosis and the rapid onset of ruminal parakeratosis in a mature dairy cow: A case report. Acta Vet. Scand. $51: 39-43$.

Steele, M. A., J. Croom, M. Kahler, O. AlZahal, S. E. Hook, J. C. Plaizier, and B. W. McBride. 2011. Bovine rumen epithelium undergoes rapid structural adaptations during grain-induced subacute ruminal acidosis. Am. J. Physiol. Regul. Integr. Comp. Physiol. 300:R1515-R1523.

Tobias, P. S., J. C. Mathison, and R. J. Ulevitch. 1988. A family of lipopolysaccharide binding proteins involved in responses to gramnegative sepsis. J. Biol. Chem. 263:13479-13481.

Van Kessel, J. S., P. C. Nedoluha, A. Williams-Campbell, R. L. Baldwin, and K. R. McLeod. 2002. Effects of ruminal and postruminal infusion of starch hydrolysate or glucose on the microbial ecology of the gastrointestinal tract in growing steers. J. Anim. Sci. 80:3027-3034.

Zebeli, Q., and B. N. Ametaj. 2009. Relationships between rumen lipopolysaccharide and mediators of inflammatory response with milk fat production and efficiency in dairy cows. J. Dairy Sci. 92:3800-3809. 